\title{
Using Reflexive, Introspective and Storytelling Tools: Towards Becoming More Autoethnographic in Academia
}

\author{
Manuel Au-Yong-Oliveira \\ GOVCOPP, Department of Economics, Management, Industrial Engineering and Tourism, University of Aveiro, \\ 3810-193 Aveiro, Portugal; mao@ua.pt
}

Received: 28 March 2020; Accepted: 17 April 2020; Published: 23 April 2020

\begin{abstract}
The aim of this article is to show how autoethnography is a useful and revealing research methodology that should be encouraged in academia, especially in higher education. With objectivity, autoethnography, which is a relatively new approach, may be a path toward deeper cultural discussions that are so important in everyday life. Moreover, autoethnography leads to important reflexive and critical observations made by students. Autoethnography is a readily accessible, low-cost methodology and thus very appealing to students and younger researchers. With this article, the author exemplifies autoethnographic accounts and narrates three different stories that occurred while trekking with three different trekking guides in Patagonia (El Chaltén), Argentina. Argentinian culture, in South America, is the focus. Researchers need to be careful of misleading statements in the literature, such as that in Argentina modesty is apparently not tolerated. We found that two of our guides and leaders - Mariano and Liz - both had modest (and pleasant) demeanors. Hence, we conclude that it is important to maintain an open mind and resist categorizing people. This is a vital point of cultural studies that is often not taken seriously. Cultures are made up of individuals and thus many differences can be found in the midst of an attempted standardization, and the desire to put everyone in the same "basket".
\end{abstract}

Keywords: Patagonia; trekking; nature; goodness of humankind; culture; individuality; reflexivity; qualitative research

\section{Introduction}

"Autoethnography is an avant-garde method of qualitative inquiry that has captured the attention of an ever-increasing number of scholars from a variety of disciplines." [1] (p. 1).

With objectivity, autoethnography may be a path that leads to a deep discussion on culture. As "Culture is a set of beliefs or standards, shared by a group of people, which help the individual decide what is, what can be, how to feel, what to do, and how to go about doing it" [2]. Moreover, autoethnography examines the differences that exist between different people, races, and regions around the globe.

In this article, the author narrates three different stories that occurred while trekking in Patagonia (El Chaltén), Argentina with three different trekking guides. Argentinian culture, in South America, is the focus. The narrator is of Anglo-Saxon origin (though mixed with Portuguese and Malaysian-Chinese) and his being multicultural related easily to the local culture in Argentina. The objective is to portray three very different personalities in the three trekking guides whom we had contact with. Books on national culture tend to set forth significant generalizations on what to expect when visiting a foreign country. This may be misleading, in some cases, and unfair in others. By having researchers increase awareness of the cultural interactions in which they are involved, not only will they become more 
aware of their personal and professional identities but important insights may result. For example, Argentina is portrayed as having a high uncertainty avoidance [3]. Does this mean that they will deal badly with strangers? That they will be unfriendly to people they do not know? Will they be more aggressive, more anxious, as suggested by Usunier and Lee [4]? The author of this article perhaps saw aggression in one Argentinian tour guide but certainly not in the other two. Such generalizations can be dangerous.

When students discuss culture in a reflexive manner, they become more aware of themselves and their surroundings by objectively attempting possible categorizations and simplifications of reality. Autoethnography is about taking notice and paying attention to life as it goes by. Autoethnography is a low-cost and accessible means of performing research, involving introspective effort by the student/researcher while not incurring any special costs.

Additionally, trekking means existing in the absence of day-to-day technology, such as e-mail and smartphone apps like WhatsApp, Instagram, and Facebook. Trekking is thus a unique activity that can involve $10 \mathrm{~h}$ (in a single day) where one is cut off from the digital world. What effect does this deprivation have on individuals? Can activities such as trekking bring us closer to the natural world?

Initially, I found that I was dependent on my smartphone: always taking photos (to the point where my family complained) and holding my phone rather than enjoying the view and the company. As time passed my dependence weaned and I gradually let go of technology.

The article examines relevant literature, considers certain methodologies, and details three autoethnographic narratives regarding the author's experiences in December 2019.

\section{A Look at the Literature}

The aim of this article is to show how qualitative research and autoethnography, in particular, is a useful and revealing research methodology. For example, Deo and Gouzouasis [5], creativity is demonstrated in a performative autoethnography via expressive prose. While music is playing, memories of the author are shared. The author is a music teacher and thus an explanation is found for this communication. The story is about Grade 9 students and the danger of drugs. I have a child in Grade 9 and I can relate to the moving message of the article. The more talented the individual, the more there is a danger of following the wrong path. Exceptional students are not immune to addiction and death. A wrong significant other at this impressionable age (14-15 years of age) may be a future detriment. Is there an element of guilt, in the author's story, for having changed jobs and for having left her former student exposed to bad influences, someone she had been so close to? Deep sobbing leaves the reader suspended in emotion: "I'll never forget Megan. I lie on my side thinking of her creative potential and what could have been" [5] (p. 180). Are we inspired to take more care of our loved ones? I certainly now try harder, with my daughters. In conclusion, true stories move us. In academia we need to lose the fear of showing emotion and we need to lose the fear of writing interesting and captivating narratives. During my doctoral studies in 2007, a prominent lecturer told me that research was not supposed to be interesting. I think that my lecturer has since changed her mind, as her research has become increasingly more interesting. I feel this change in society happening as we speak. Academia has to find a new place for itself.

In Au-Yong-Oliveira, Branco and Costa [6], the author speaks of his experience abroad, in the Maldives islands inhabited by native citizens rather than tourists. There, the author comes into contact with a local traditional festival and is surprised by the harmony amongst the population, who practice Islam. Women and men stood on opposite sides of the street without visible dissatisfaction. The media often states that there is frustration and abuse in these environments, especially of women. The author instead saw amicability, accord, kinship, and, above all, peace. Furthermore, technology (i.e., smartphones and selfies) has showed that culture is more global than is normally supposed and advertised (Figure 1). Cultures may maintain certain traditions while also adapting to technology. Technology brings people closer together across the globe. Autoethnography involves reporting on what is supposedly different or similar between diverse national cultures. 


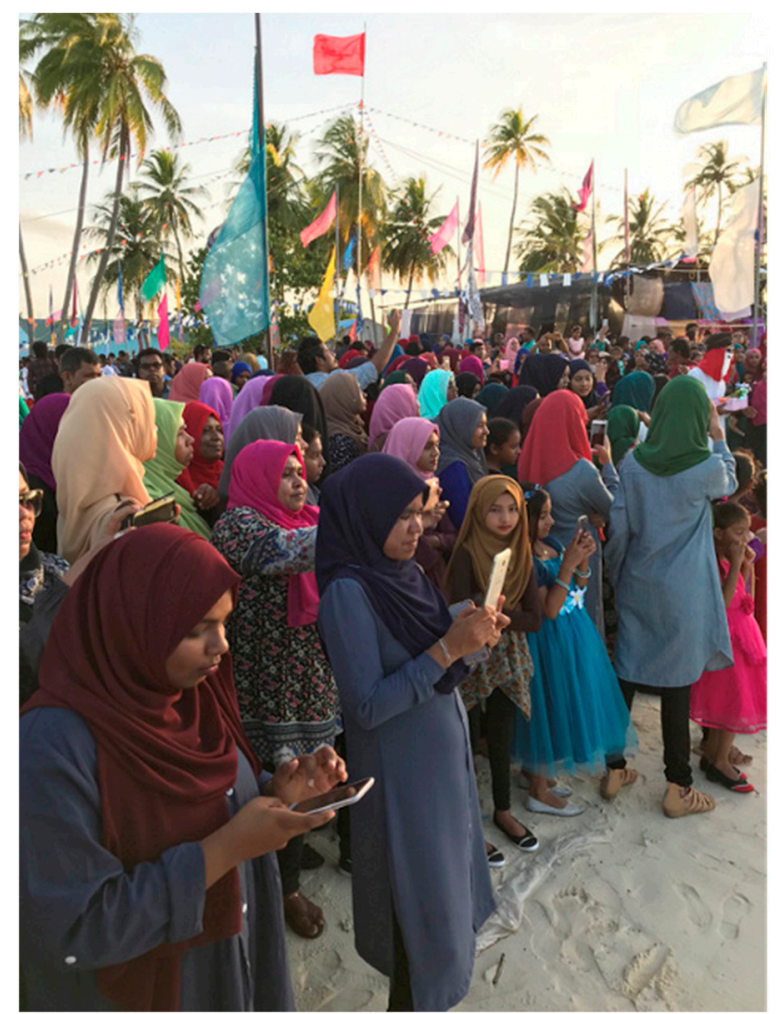

Figure 1. Technology, smartphones, and selfies: noticing what is supposedly different or perhaps similar between different national cultures [6] (p. 856). Reproduced with permission.

Oito [7] is an author of another example of how autoethnography communicates emotions, specifically regarding whiteness, namely in a classroom in the United States. The article asks if teachers are prepared to be confronted by black youths in urban classrooms, detailing "the psychic pain that racism inflicts upon the racially othered children and youths who navigate urban classrooms under the scorching glare of whiteness" [7]. Only someone in a room "stuck in stillness" [7] (p. 251) may speak of glares and of "the loudness of the loaded silence" [7] (p. 251). Such vocabulary is often absent from academic discourse and "in the name of science" we are encouraged to be formal and distant. Yet is it not academia's purpose to educate both the younger as well as older generations, aiming for change and for development, aiming to reach out? How can we reach out and touch souls if we cannot use the full force of emotion derived from our words and experiences?

Storytelling involves sensemaking and plays a significant role in autoethnography. Prominent authors have "put forward a rebalanced model of sensemaking to make the sensible once again sensible and open up the sensemaking perspective to understand learning as a process that is more than mere interpretation" [8] (p. 3). How may we conquer and inspire our students if not through language and heartfelt prose, which communicates meaning and sense to the lives of those who are interested and who take the time to read our narrative? We may not have more than a single chance at such a change.

Not to say that this type or any type of storytelling is not a complex process. Past authors have framed it thus: "To make sense through processes of organizing and to find a plausible answer to the question 'what is the story?' requires a fusion of sufficient complexity of thought with simplicity of action, which we call simplexity" [9] (p. 5). Storytelling may require a confidence in the use of the correct language that other scientific methods do not require. Storytelling, including of our own experience, is a complex matter. Yet are we not living in complex times of exponential technological change that call for radical solutions to engage our intended audience?

With regard to Argentina, it is stigmatized as a politically, economically, and socially difficult country that has an oversimplified, acritical, and ignorant acceptance of poor leadership [10]. However, 
Argentina is culturally idiosyncratic and differences are tolerated [10]. Argentinian culture inspires indulgence (featuring a high score of 62). Argentinians love to live joyously and have fun, even if in a loud fashion. Argentinians embody qualities such as sharing, collaborating, and socializing [11]. Argentina has a middle score for collectivism/individualism (46) and registers a high uncertainty avoidance score (86). This leads to an excess of rules and corruption [10,11]. Argentinian culture expresses masculine traits (featuring a score of 56 [11]), meaning that an achievement orientation is present, including a desire to excel.

As with all cultures there are exceptions and the above is but a generalization. This is an important point of cultural studies often not taken seriously: cultures are made up of individuals and many differences are found, even amid an attempted standardization and desire to put everyone in one "basket" [3,12]. However, as is shown below, we never know what we shall find at a travel destination (or, indeed, in our home countries).

\section{Methodology}

"Higher education has recently been recognized as a key driver for societal growth" [13] (p. 1) and research performed by students is an increasing requirement and expectation of higher education institutions. Students thus need to seek new and accessible avenues for their research endeavors. Autoethnography is one such avenue.

This study addresses two research problems: 1) why is autoethnography important? and 2) how may we help students produce more reflexive and introspective research through storytelling? In other words, how can we help students become more autoethnographic in academia?

The research design for relating the research problems "to relevant and practicable empirical research" [14] (p. 56) is an elaboration on the "framework for data collection and its analysis" [14] (p. 56). Furthermore, the research design is "a statement describing how the research is intended to be conducted" [15] (p. 193).

To aid recall, the use of a research diary, with regular entries, is suggested. The researcher will be able to maintain a trail of research activities and of the thinking processes developed during the research [15]. The research diary will be more or less essential depending on the length of the research period. For example, this study, which is exploratory in nature and in which the author told his own autoethnographic story, involved the description of events that spanned three days during a holiday trip, a period of time adequate for such a study [16].

Autoethnography is controversial but, if done rigorously, may lead to interesting results [17]. For this research study, a research diary and field notes were taken as the events took place (or soon after), to aid recall. Field notes for this study were of strategic importance.

Field notes may be of three types: methodological, descriptive, or analytic [18].

Concerning my methodological notes on collecting data, I suggest using a smartphone. Indeed, my smartphone has served me well on more than one occasion. Because smartphones are a natural part of contemporary environments (whereas a note pad or camera may make participants feel unduly nervous and wary, thus affecting the outcomes of the research effort), one may take notes, photos, videos, or do audio recordings without seeming too intrusive in the field.

"Descriptive notes are the meat and potatoes of fieldwork" [18] (p. 397) and they result from visual observation and listening. Descriptive notes may be in large volume. An advantage of using a smartphone to register notes is that one may use the "find" function to locate certain entries to our notes, according to a key word, thus saving time and frustration. This type of qualitative research may be tiresome at times and is often much more troublesome than doing an online survey.

Finally, it is also important to enter analytic notes in our research diary and field notes. This type of notetaking is essential and a unique contribution to our research. Analytic notes are often about small details and researchers should not be deterred from notetaking, even if the notes seem marginal or trivial in the grand scheme of the research. 
Autoethnography is autobiography plus ethnography. It involves introspection [17] with regard to experiences involving the author (as storyteller). The main contribution lies in being able to see what is different. Handwerker [16] states that one has to "remember the basics [ ... ] to produce ethnography, focus on similarities and differences among your informants". Furthermore, one has to consider, in the research design, that "cultural differences reflect variation in personal experiences. Culture evolves." [16] (p. 267). Table 1 summarizes how ethnography "flows out of a theory of culture" [16] (p. 274) and suggests elements to be included in the research design. Researchers should use labels and names to identify experiences. Definitions, in turn, will act as differentiators, especially when situations are ambiguous. Finally, intellectual or emotional associations will aid in the creation of meaningful mental constructions.

Table 1. Cultural phenomena, adapted from [16].

\begin{tabular}{cc}
\hline Cultural phenomena & Purpose \\
\hline Labels, names & Identifiers of experience \\
\hline Definitions & Differentiators \\
\hline Associations & Meaningful mental constructions \\
\hline
\end{tabular}

Autoethnography is also reflexive and its main beneficial qualities are in education, as it "facilitates our questioning and moves us beyond our own taken-for-granted assumptions and sense-making of the social world, both professionally and personally" [19] (p. 173). It is also useful as it furthers research on different cultures and shows people customs, beliefs, and values that may be distinct in certain parts of the world. Autoethnography "is a relatively new approach to academic research, which at present would only be accepted by a small community of scholars" [15] (p. 16). It is a qualitative research method that relies on narrative and words [15]. Rich description [20] is essential in autoethnographic accounts: "One has to peek at one's immediate experience as if from a unique 'cultural window" [21] (p. 58) (Figure 2). Therefore, I seek an "autoethnography that allows for innovation, imagination, and the representation of a range of voices in qualitative inquiry while also sustaining confidence in the quality, rigor, and usefulness of academic research" [1] (p. 1). I herein hope to make a contribution in that direction.

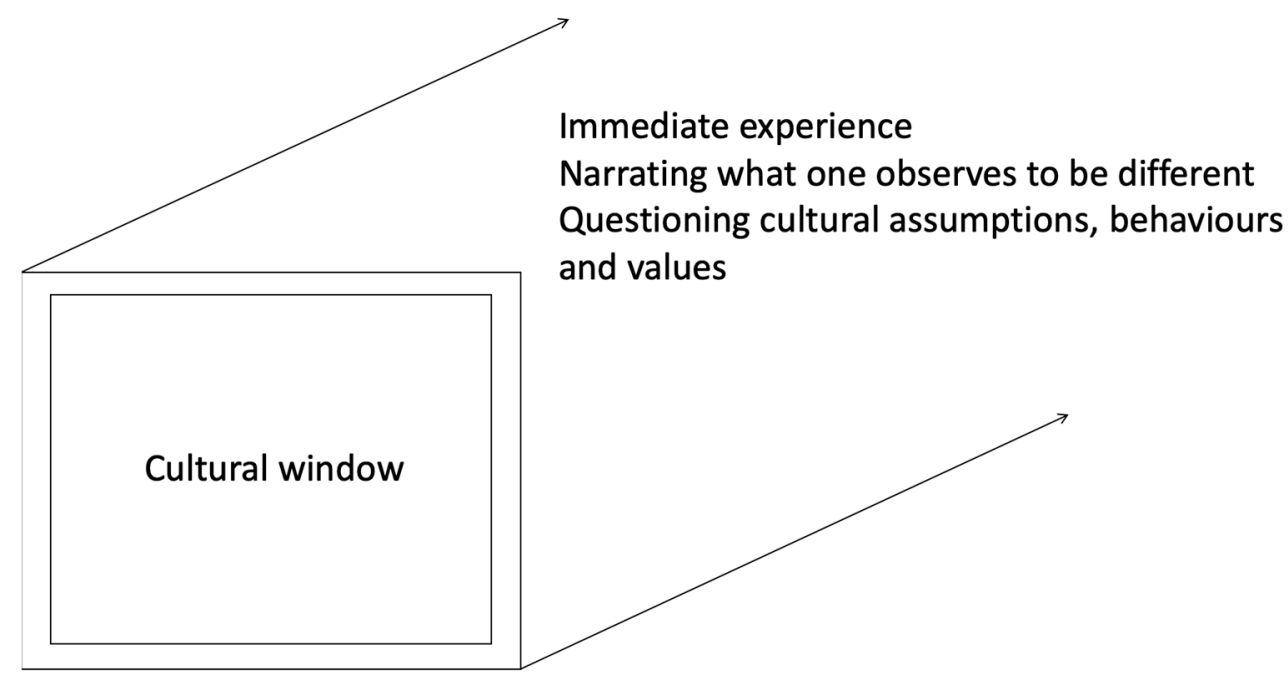

Figure 2. Autoethnography involves peering from a unique "cultural window" [21] (p. 59). Reproduced with permission. 
The autoethnographic stories told in this study involve my family's December 2019 holiday trekking trip to El Chaltén, in Patagonia, Argentina. I hope to not only share my views on what I saw and experienced but also to transmit new knowledge on culture.

While on holiday, I asked those who I was interacting with, and thought would be a part of my storytelling, whether they consented to me writing about them. It is important to get early authorization (so as to not be disappointed later, after writing the article) and to exchange e-mails and contacts for posterior use. For example, you may later send the stories to the participants, for verification and validation purposes. In this study, the two names of the guides are real (Mariano and Liz); the third guide, who is not named, has had some details withheld, to make sure that he is not identifiable and to ensure that he is completely anonymous. To date, everyone who I have asked to name in my autoethnographic studies has agreed to be involved. I must also admit that some subjects were surprised at me wanting to research and write during a holiday. However, I see holidays as a unique opportunity to meet and interact with a culture new and unknown to me, thus providing good research opportunities.

This research study was shared with one of the tour guides, Liz Reyes, who confirmed the validity of what was written.

\section{Autoethnographic Narratives}

\subsection{Story 1: At the Mercy of A Bad Trekking Guide in Patagonia, El Chaltén, Argentina}

We had a hurried discussion amongst ourselves. Should we leave our trekking guide a tip? If so, how much? Should we invite him for a drink when we have finished the trek?

The 20-km trek to Laguna Torre had been a hard one. It was Christmas day (25th of December 2019) and perhaps we should have stayed at home and kept warm and dry. The rain at the top of the mountain (Figure 3) came down sideways in torrents, due to the wind. We were soaking wet and had to trek another three hours down the same route which had brought us to the summit.

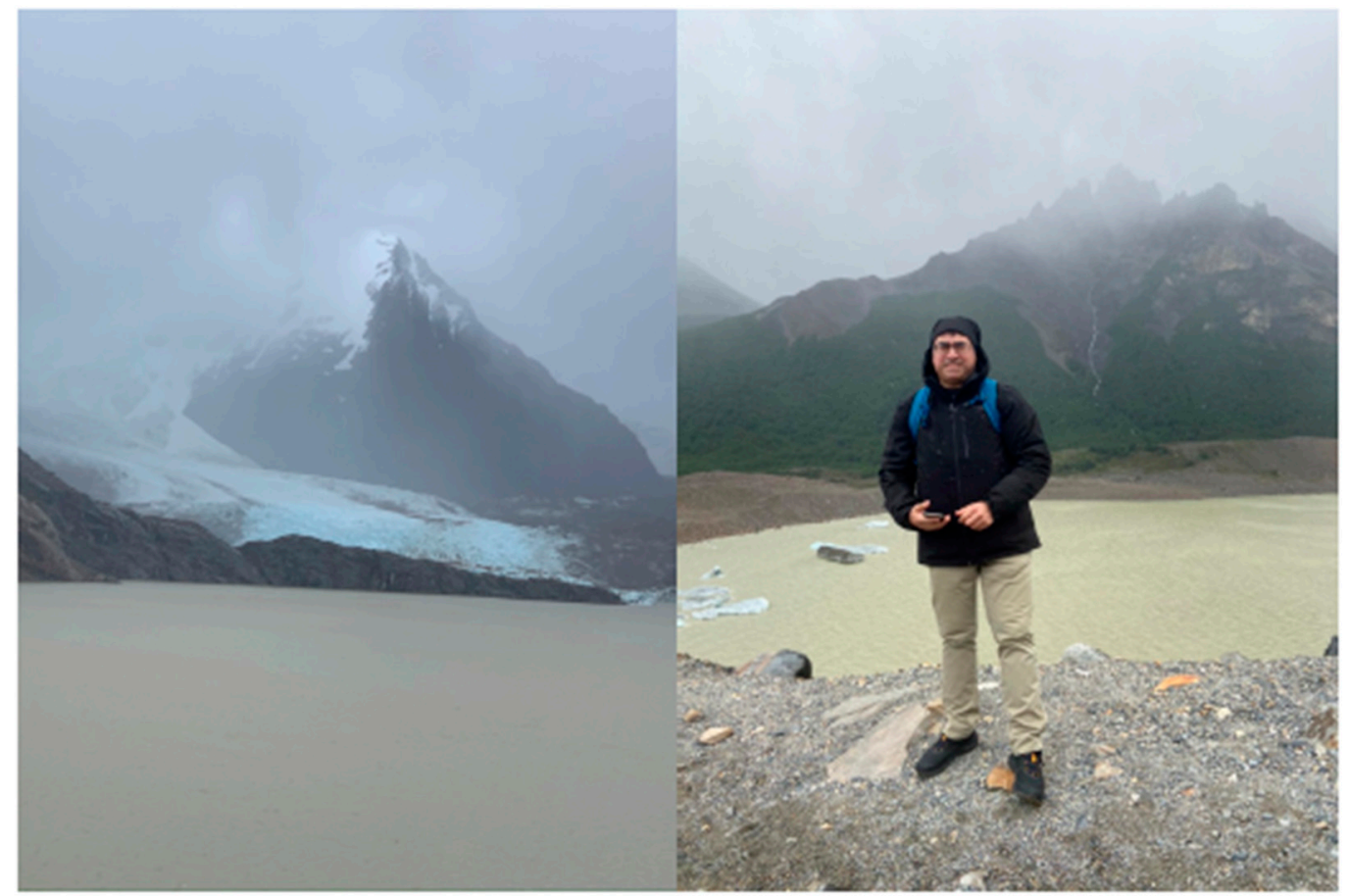

Figure 3. Arriving at Laguna Torre in bad weather. El Chaltén, Argentina (December 2019).

Our trekking guide, we discovered, was pressing to get home early, due to our late start (we had asked our travel agency to start later, as we were delayed the day before, due in fact to the same 
travel agency having made a mistake). For the duration of our trek, our trekking guide did not stop to see if we were keeping up, nor did he stop for us to have a look at the view. He stopped either to relieve himself in the woods or to put on his coat and gloves. When the rain stopped, he stopped to take his coat and gloves off. We were not the center of his attention; rather, he was the center of his own attention.

I was curious as to what motivated our trekking guide. Did he resent us, being apparently affluent Europeans? He did say that he had never been to Europe, that neither it nor the USA interested him.

"Are you married? Do you have kids?" I gathered the courage to ask. Our guide then gave me a brief account of his life.

He had been married before, yes, and from his first marriage had had a child, now 22 years old. He had never wanted more than one child. Children are time-consuming, he said, and difficult to raise. Besides, they are very expensive. I told him that in Europe, having one child was normal. He replied: "Here [in Argentina] it is not like that. People have three, four, or five children. And they never break out of being poor.

"I am now separated from my second wife. I believe I did not come to this world to be unhappy or to suffer. Thus, if something annoys me I just leave. I do not like children." This last confession came as a surprise to me, his candid admission that he did not like children. I had two young girls, aged 11 and 14, who were with us during the trek.

Earlier, the trekking guide had said that he went to Asia during the winter to teach Spanish. I asked him if he stayed in Asia for three months or more. He replied, "I stay for five or six months. I go when it gets boring here. I take off. I am very selfish, I suppose."

I appreciated his candor and honesty.

Our trek was coming to an end and I finally had the answer to my question, concerning the tip for our trekking guide. As we parted, he instructed us to our hotel: "Your hotel is quite close. There are some steps over there. Go down them, all the way down, then turn left and left again, and then right. Hotel de Las Piedras. You cannot miss it. This is my neighborhood, this is where I live. I shall stay here."

The houses in the neighborhood were of different shapes and sizes, but were generally very small and in some cases (if not all) not projected by an architect or engineer.

The trekking guide cordially shook our hands. I shook my head at my wife. No tip; she understood. Later, I explained that our trekking guide was not interested in tips. He worked to get by, nothing more, had no ambition other than that. Being nice only up to the point whereby he could keep his job.

My stepson ventured that if our trekking guide did not like children then he should not be a teacher. I agreed. However, everyone who does not like their job, in my opinion, has the wrong job. The vast majority of the world's population probably falls into this category. I have not liked all of my jobs during my lifetime, yet the bills must be paid. We cannot all be like Cristiano Ronaldo, the ingenious footballer, who I imagine loves his job. Yet we should still aspire to love our work like Ronaldo, should we not? However, what if we do not have the chance or opportunity? Preparation and luck make for opportunity; be prepared and you may get lucky. Otherwise, you may end up working for customers you hate or, at the very least, dislike. This is, at all costs, a life I do not want for my children.

I shall thus work to educate and prepare. Should not all good parents do the same?

\subsection{Story 2: A Challenging Trek in El Chaltén, "Senda al Fitz Roy"}

Thankfully, our next mountain guide was exceptional.

Mariano Casé was 35 years old and had been a mountain guide for 13 years, 10 of which were in El Chaltén. Mariano said that he had to have an outdoor job; if he were to be locked inside all day he would be very unhappy. He had a passion for nature and fresh air. Mariano was patient, informative, and had a pleasant and happy demeanor (Figure 4). 


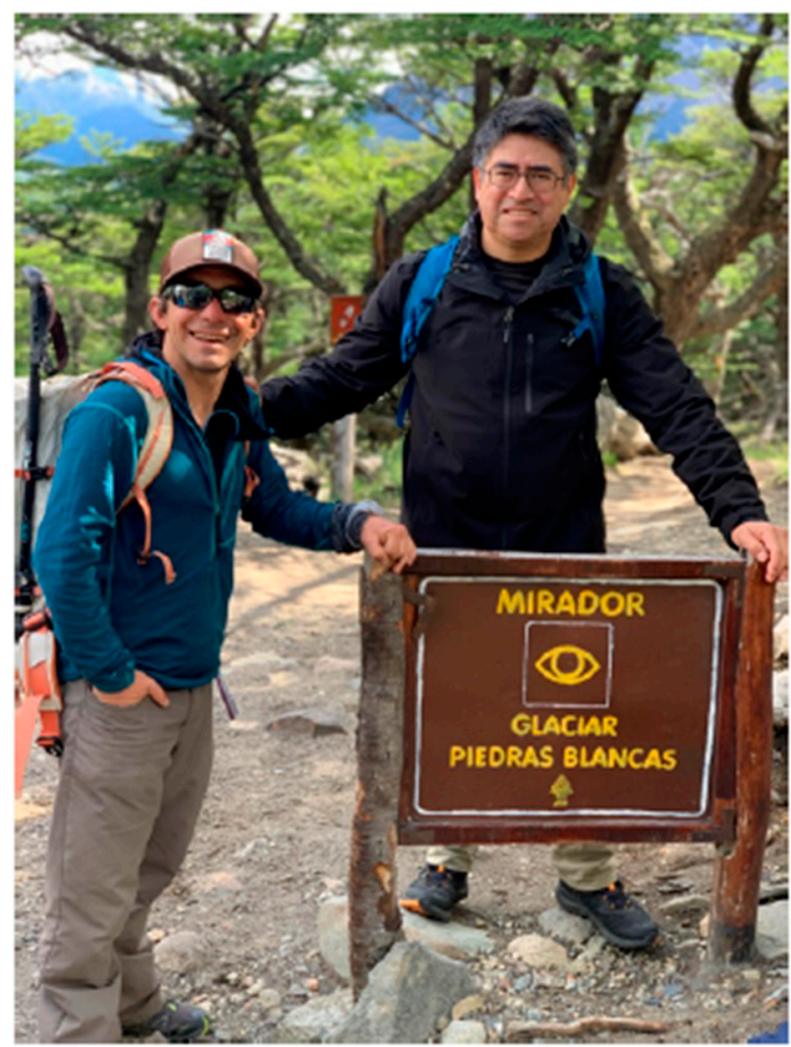

Figure 4. With our trekking guide Mariano Casé. A memorable trek on Boxing Day, 2019.

The Fitz Roy trek toward Laguna de los Tres involved a steep one-hour climb, to $1200 \mathrm{~m}$. The first one-third, before resting, was done under the scorching hot summer sun. I was exhausted yet motivated to get to the top as the sun was shining. The visibility would be good.

As I trekked, I followed Mariano's footsteps exactly, placing my feet where he put his. It was an uneven and rocky climb, which turned into steep switchbacks nearer the top. Being with an expert trekker gave me the confidence I needed to make it. This phenomenon may be considered as positive contagion [22]. I did not need to think, but act. In following a competent leader, my performance and perception of the task improved-the mountain did not seem so steep and difficult, after all.

Mariano encouraged me to get to the top of the Fitz Roy trek, to see Laguna de los Tres. Without him I would not have made it. I saw that this $22-\mathrm{km}$ trek and that challenging part of the journey were a test of character. Many thoughts went through my mind as I pulled my $84 \mathrm{Kg}$ overweight body up the mountain. I was exhilarated when I made it to the top of Laguna de los Tres (Figure 5). The view was breathtaking. The sky was clear. I felt that all was well in the world. Mariano high-fived me. It was as much his victory as it was mine. "Just 2- minutes to go . $15 \ldots 10 \ldots 5 \ldots 2 \mathrm{~min} \ldots$ you are almost there!" Mariano had said. We are so much stronger in pairs, collaborating. Alone, I would have not attempted the climb at all (due mainly to an injury I incurred in my youth).

However, certain challenges are also a personal and lonely journey. I sang and hummed to myself while climbing. Said positive words, positive self-talk: "You can do it."

Mariano was very positive. My stepson reminded me afterwards to write about positive experiences and positive people. He was right.

My youngest daughter lost her cell phone and jacket on the way up the mountain. After the trek, Mariano took the trouble to go to the lost and found booth and managed to recover her items. This was beyond what was required of him and we were delighted. Late in the evening, Mariano came to our hotel to give us my daughter's lost items. He had a drink with us upon arrival in El Chaltén. 
This was Argentinian culture at its best. Cheerful and somewhat loud socializing. Indeed, it was a memorable trip on Boxing Day 2019.

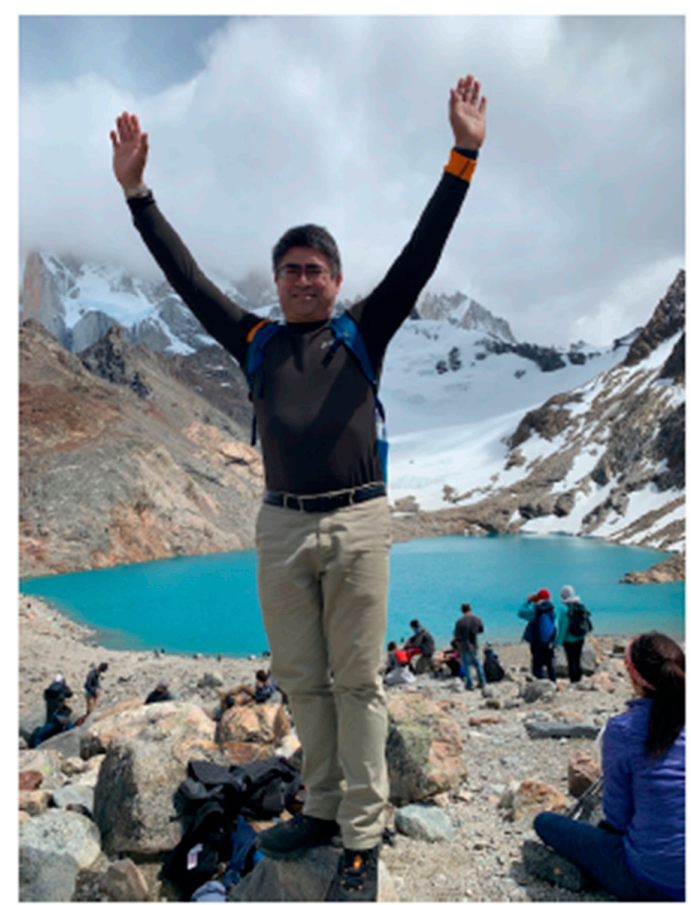

Figure 5. Laguna de los Tres, Senda al Fitz Roy, El Chaltén, Argentina (December 2019).

\subsection{Story 3: The Trek to Laguna del Diablo and the Principle of Reciprocity}

Our last trek in El Chaltén was to Laguna del Diablo (Figure 6) and it was a difficult one. Although it was just under $17 \mathrm{~km}$, we trekked in heavy rain in the woods on uneven ground that sloped uphill and upriver. We had to climb over roots and across wet areas. I was thankful that I had waterproof trekking shoes. However, not all of our group was so lucky. Having wet socks was unpleasant and not everyone packed waterproof trousers.

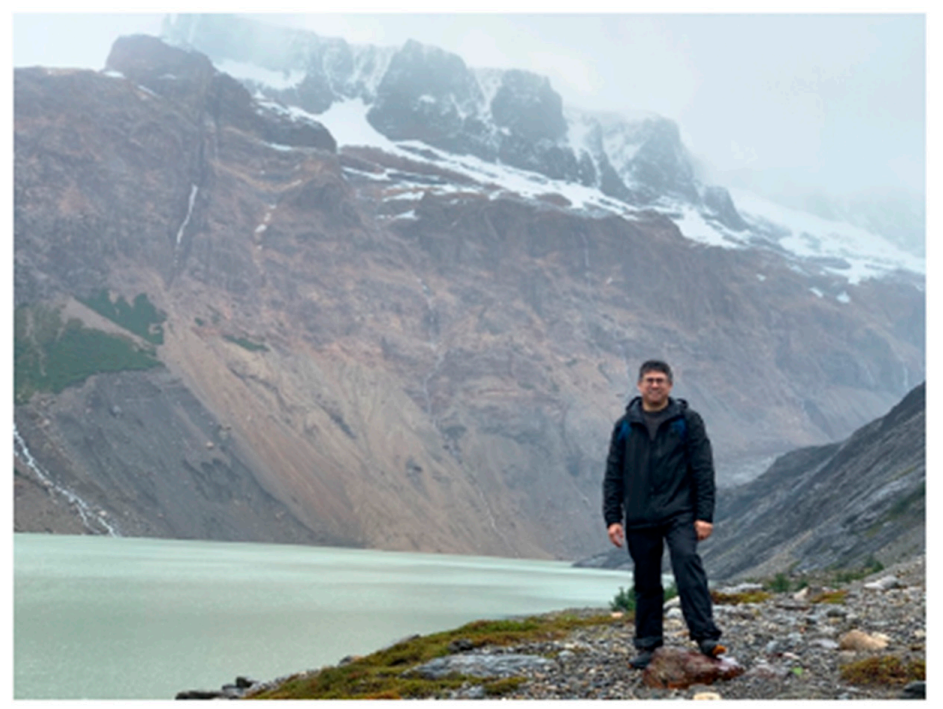

Figure 6. Laguna del Diablo in El Chaltén, Argentina (December 2019). 
Our trekking guide was 30-year-old Liz Reyes. She had worked 10 years as a tourism guide and had only recently qualified to become a trekking guide. They were distinct professions, Liz said. Thus, she was inexperienced and this perhaps made her better as a trekking guide. Liz was eager to please and was flexible and attentive, taking photos and videos of us upon our request. Do we get spoiled by the routineness of our work? Should we change jobs often, perhaps every 10 years, to avoid that?

Again, I benefitted from following Liz up the path. When I experienced difficulty in the ascent, in the rain, I followed Liz and soon found the "transference of beneficial properties" (again, a positive contagion) [22] (p. 1).

The sun came out after lunch. This changed our moods. There is nothing like good weather and sunshine.

Liz let me lead on the trek back. This was a good practice, as trekking guides move fast and agilely, perhaps leaving weaker trekkers behind. Liz allowed a weaker trekker, like me, to set the pace while she brought up the rear. This did not mean that Liz did not pay attention to us. When my youngest daughter fell, tripping on her undone shoelaces, Liz oversaw me tie a better shoelace knot for her, one that would not come undone.

I must say that I was taken aback by the culture of sharing and socializing institutionalized in Argentina. Liz shared her "mate" (a local form of tea, which she made with her flask of hot water and special cup and "mate" leaves) with our driver, going back to the hotel. On the way to El Chaltén, from El Calafate, Liz had done the same with us (by coincidence, we had travelled together). This was something I had perhaps expected to see in an Argentinian culture, a culture of proximity and friendliness.

Our two trekking guides, Mariano and Liz, perhaps being younger than our first trekking guide, were more hopeful, helpful, and positive. Whether genetic or acquired during one's childhood or later in life, there are differences between people. There are many good people, but there are bad people too. Give and thou shall receive. The principle of reciprocity [23]. Yet not everyone wants to give first.

\section{Discussion}

Autoethnography is a voyage of self-discovery for the researcher, who is given to both introspection and observation. Major objectives of academia include teaching one how to observe and be self-aware (of the shortcomings, differences, and strengths of one's culture). Self-scrutiny leads to "the formation of an individual's professional identity" [24] (p. 339), which is an objective of contemporary education [24].

Autoethnography approximates realities-the theoretical and the "real" (i.e., professional). One needs to consider that "the classical design of the pedagogical course does not favor the maximum attainment of the predefined objectives. The break between academic knowledge and professional knowledge is the main cause [... ] It is a question of adopting the reflexive posture to maximize the relations between the theoretical bases and the teaching practices by exploiting all the tools offered" [25] (p. 300). Tools such as introspection, reflexivity, and storytelling.

The term autoethnography is often absent from the index sections of methodology manuals $[18,26,27]$ and absent from the content of such books. Autoethnography is in its infancy and is seen to be the result of pioneering work by Ellis, Adams and Bochner [28] less than a decade ago.

On the other hand, a 15 April 2020 search on Scopus.com with the search terms "autoethnography" or "auto ethnography" in all fields revealed 10,696 documents. Therefore, autoethnography has made a place for itself in one of the main academic databases for business studies and the social sciences.

One such document on Scopus equates autoethnography to hope, stating further that "autoethnography turns the research lens inward and takes seriously the idea that the study of self is legitimate. It allows for the exploration of reflexivity and encourages a journey that plumbs interior space" [29] (p. 741). Autoethnography is important because it presents and secures meaning to situations and relational experiences [29].

The need for autoethnography may arise where: (1) There is a close relationship between young researchers and their lecturers or supervisors; autoethnography is not easy to undertake and involves 
courage, guidance, and savoir faire; (2) there is a lack of funding for in-depth research efforts such as those involving several hundred interviews done abroad with executives in a foreign language (such an effort may involve hiring a research firm to gain access and do the field work, which is often beyond the financial possibilities of researchers in less affluent countries); (3) time is lacking for more "regular / standard" research efforts by lecturers in poorer environments who may be overworked in an education system where there are more hours lectured, per week, by lecturers than in richer countries; (4) the researcher is able to live life and analyze that life, as it occurs, at the same timetravel is beneficial to this occurrence; (5) certain cultures (e.g., Anglo-Saxon) are less personal and more distant than, for example, Latin cultures, and thus may be less inclined to write reflexive and introspective stories about their lives. Yet such an inclination will certainly differ from individual to individual and generalizing who will want to perform autoethnographic research should be avoided.

Autoethnography may open new research avenues, leading to the generation of important knowledge, and thus deserves more attention, so that its popularity in future may increase further.

During my first trekking trip, I discovered nature, socializing, and self-actualization. In the outdoors, one suffers from the elements, rain, wind, and snow, and we must accept what nature offers us. We may travel $10 \mathrm{~km}$ for a view only for clouds or fog to get in the way. Trekking, as with many other activities, is unpredictable. With no cell phone connection or Internet to distract us, we are left alone with our thoughts. Additionally, we may choose to talk to our trekking companions. We may observe nature. Thus, I have found that trekking-lovers are nice people. Most do not litter or otherwise harm the environment.

We also witnessed first-hand how selfless trekkers can be. When my daughter lost her mobile phone and jacket, someone carried these objects nine kilometers to hand them in at the lost-and-found booth, in town. Moreover, we were impressed by our guide who found these valuables.

Travelling abroad allows one to experience a different culture and thus ideally reflects the process of autoethnography, as culture is a central aspect of this approach [28]. Autoethnography exists "in order to understand cultural experience" [28].

Travel is about getting to know how other people live. In this study, we saw how we had different trekking guides, despite all being from Argentina. From the selfish, indeed living only for oneself, to the collaborators and competent leaders. At times, we may have forgotten the tremendous diversity found in a country or small environment, such as El Chaltén. Hofstede [3] (p. 9) defined culture as "the collective programming of the mind that distinguishes the members of one group or category of people from another," which I find inaccurate and misleading. Is it an exaggeration to claim that being humane and loving life are virtues found everywhere? One has to only read the news to read stories about war and other atrocities. In sum, all Argentinian individuals do not share the same traits, despite what we are led to believe in an effort to simplify life's complexities.

Being more aware that theories abound, but are different from laws - in that they are less universal - will lead to the creation of greater and more careful theorists.

Introspection is seen to be self-healing to one's woes, which is another important benefit to writing reflexive pieces. Becker [30] chose to describe individual reactions to chronic pain (the survey had 192 responses, from eight countries). Pain, they found, is related to identity construction. What can be more personal than such a characteristic as one's reaction to pain? The article also adds value when it analyzes pain according to those who experience it. It is an article about reflexive thought and introspection. Surprisingly, those in chronic pain want to narrate the pain they are feeling: "For providers to better understand patients' chronic pain, results indicate they would like providers to inquire about how pain impacts their daily activities, relationships, work responsibilities, goals, and dreams using open-ended questions. These low-stake questions can facilitate emotional disclosure, increase feelings of support, and allow for co-morbid linkages." [30]. The fact that the patients' knowledge is subjective does not affect the results and the author concludes that the exchange positively deepens communication, with emotional benefits and increased well-being, as other authors have similarly concluded [29]. 
Reflexive introspection "challenges canonical ways of doing research and representing others, and treats research as a political, socially-just, and socially-conscious act." [28]. By making students and researchers more socially-conscious, the problem of long-term learning may be solved, as individuals narrating stories about their experiences will necessarily ask questions related to their area of training be it politics, sociology, tourism, or business management. Students will no longer act without thinking, merely memorizing without understanding, as is often the case in higher education [31].

The autoethnographic stories told herein exemplify how people are different, as each person has inevitably had a unique path that he or she may in turn interpret differently. How we view ourselves and our environment may lead us to frustration and a sense of rebellion against the "cards" that life has dealt us, or may lead us to additional learning and an evolution of character. By being open to learning, we become open to change. Not everyone views change in the same way and not everyone is open to change. Like our first trekking guide, some have made the decision to close themselves off to the world, peeking out only to satisfy their own needs and to collaborate as little as possible with anyone else in the process. The other two trekking guides, on the other hand, acted as if they were spreading happiness and goodness in the world.

Beware of statements in the literature such as "in Argentina, Bolivia, and Mexico, modesty seems not to be tolerated" [10] (p. 683). Two of our guides and leaders - Mariano and Liz - both had modest (and pleasant) demeanors. Keep an open mind and do not be quick to categorize people. Life will be fuller and less disappointing, in a good way, as we learn again, each day, that goodness exists (Figure 7).

\section{Educating through autoethnography to be reflexive and introspective}

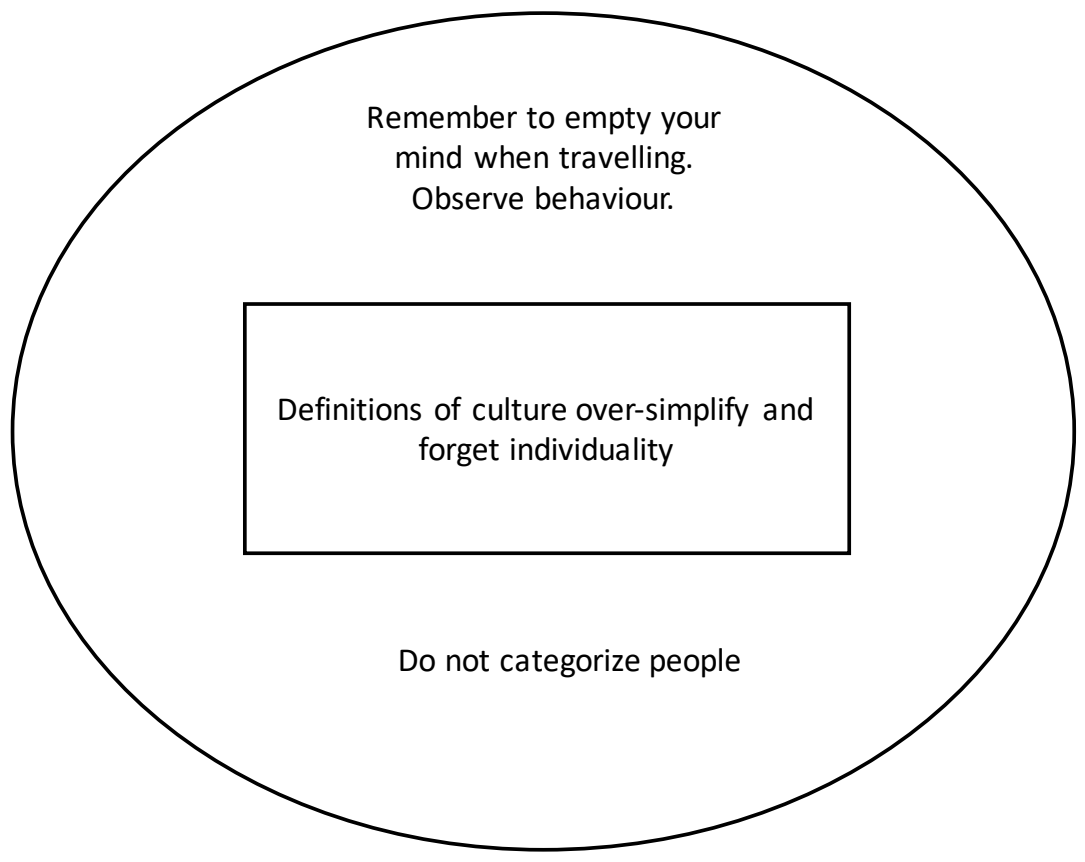

Figure 7. Observe and do not categorize people when travelling.

After writing this study, the author is more aware of his background, culture, and identity. The cultural window, mentioned in Figure 2, may be turned in on oneself. The advice to not categorize people, in Figure 7, may be more significant if one considers one's own self.

In the author's case, being seen as a Portuguese citizen, may be misleading. Having been born in London, in the UK, where he spent his childhood, the author is also English. This, however, is misleading, as the author was brought up in a traditional family by his mother, who is Chinese, but who grew up in Kuala Lumpur, Malaysia. The author's "profile" is perhaps alien to previous categorizations by cultural researchers. Certainly the author has not found a classification of his own 
culture; surely, he is a mixture of a number of the cultures mentioned above. If one chooses to add all of his or her experiences together, concerning work, sport, family, travel, personal tragedy, and other difficulties, one notices that categorization is an impossible task. Yet the literature readily categorizes millions of individuals from a country in the same manner. "No one possesses a single culture," warns Handwerker [16] (p. 268). We are all the result of a complex network of relations [16], originating since we were born or perhaps even before that, as our parents raised us as they were taught, and according to what they believe in [4].

If academia is to remain relevant, new research paths and different conclusions need to be arrived at. Only then will humankind progress toward greater unity and collaboration. Should not these be the objectives of higher education, in general? A long path remains to be trodden. Time is of the essence. As the planet suffers, as wars rage on, and as perhaps humanity seems to be lost. Academia is in need of a revolution. Autoethnography may be an important first step in the right direction. We can only hope that this is the case.

\section{Autoethnography in Academia: Concluding Remarks}

In late 2019, I asked nearly 100 postgraduate students to write their own autoethnographic stories in an essay. I asked: (1) How their group projects had gone and what were the challenges, Was it better working in a group than working alone? How was it to work, in some cases, with foreign Erasmus students? Did group leaders emerge during the assignments? I also asked if and when (2) they were innovative in their personal lives. For this data collection effort, students could choose to sign their work or leave it anonymous. Some students handed their stories to the lecturer in class; others sent them by e-mail. In each case, the students took the exercise seriously, and wrote honest, earnest accounts. For example, one student stated the following, regarding conflict and creativity: "As ideas within a group collide, sometimes arguments ensue that may lead to new brilliant ideas; but, on the other hand, these arguments may condition the development of the project." On the subject of leadership and flexibility, another student stated: "At times, one has to step up to be the leader of the group; at other times, one has to take two steps back and let another element pursue his or her idea just so that he/she may understand that the idea is not plausible."

Through the group work done by students, one may quickly perceive the existence of a deep learning process as important or even more important than the traditional learning that occurs in class. A psychologist and expert on education, Howard Gardner, from the Harvard Graduate School of Education, stated: "I discern two legitimate reasons for undertaking new educational practices. The first reason is that current practices are not actually working. We might think, for example, that we are educating young persons who are literate, or immersed in the arts, or capable in scientific theorizing, or tolerant of immigrants, or skilled in conflict resolution. But if evidence accrues that we are not successful in these pursuits, then we should consider altering our practices ... or our goals" [32] (p. 10).

I hope to have helped provide an alternative route to education by showing how students can become more aware of the processes in which they are involved in, processes that may lead to long-term behavioral change. What more could we ask of academia? "Education must be lifelong" [32] (p. 9) and what can be more permanent than that which has happened to us? Reflexive introspection is just one path to achieve change in education and it is an important path if followed rigorously and objectively.

Other professionals in the field of education recommend "the type of subjective deep exploration that autoethnography supports. For us, it has functioned as both a methodology and a psychological life support" [29] (p. 741). Clearly, we are not alone in observing an important alternative research method for the social sciences and business studies, in particular.

Funding: This research received no external funding.

Conflicts of Interest: The author declare no conflict of interest. 


\section{References}

1. Wall, S.S. Toward a moderate autobiography. Int. J. Qual. Methods 2016, 15, 1-9.

2. Goodenough, W.H. Culture, Language and Society; Modular Publications, 7, Addison-Wesley: Reading, MA, USA, 1971.

3. Hofstede, G. Culture's Consequences: Comparing Values, Behaviours, Institutions, and Organizations Across Nations, 2nd ed; Sage: Thousand Oaks, California, CA, USA, 2001.

4. Usunier, J.-C.; Lee, J.A. Marketing Across Cultures, 4th ed.; Pearson Education: Essex, UK, 2005.

5. Deo, C.; Gouzouasis, P. To build a home. Qual. Res. Psychol. 2020, 17, 178-181. [CrossRef]

6. Au-Yong-Oliveira, M.; Branco, F.; Costa, C. A evolução cultural graças à adoção da tecnologia e ao fenómeno “Mix-Tech"—Um estudo exploratório baseado na observação. Rev. Ibérica Siste. Tecnol. Inform. 2019, E17, 854-869.

7. Oito, E.O. Thinking through the flesh: A critical autoethnography of racial body politics in urban teacher education. Race Ethn. Educ. 2019, 22, 250-268. [CrossRef]

8. Colville, I.; Pye, A.; Brown, A.D. Sensemaking processes and Weickarious learning. Manag. Learn. 2016, 47, 3-13. [CrossRef]

9. Colville, I.; Brown, A.D.; Pye, A. Simplexity: Sensemaking, organizing and storytelling for our time. Hum. Relat. 2012, 65, 5-15. [CrossRef]

10. Altschul, C.; Altschul, M.; López, M.; Preziosa, M.M.; Ruffolo, F. Argentina: Crisis of guidance. In Culture and Leadership Across the World: The GLOBE Book of in-Depth Studies of 25 Societies; Chhokar, J.S., Brodbeck, F.C., House, R.J., Eds.; Routledge: New York, NY, USA, 2012; pp. 657-687.

11. Hofstede Insights 2019. Argentina. Available online: https://www.hofstede-insights.com/countrycomparison/argentina/ (accessed on 19 March 2020).

12. House, R.J.; Hanges, P.J.; Javidan, M.; Dorfman, P.W.; Gupta, V. (Eds.) Culture, Leadership and Organizations-The GLOBE Study of 62 Societies; Sage Publications: Thousand Oaks, CA, USA, 2004.

13. Adriansen, H.K.; Madsen, L.M.; Jensen, S. Higher Education and Capacity Building in Africa: The Geography and Power of Knowledge under Changing Conditions; Taylor and Francis: Abingdon, UK, 2016.

14. Ghauri, P.; Gronhaug, K. Research Methods in Business Studies-A Practical Guide, 3rd ed.; Pearson Education: Harlow, UK, 2005.

15. Remenyi, D. Dictionary of Research Methods and Concepts, 2nd ed.; ACPI: Reading, UK, 2017.

16. Handwerker, W.P. Quick Ethnography; Altamira Press: Walnut Creek, CA, USA, 2001.

17. Pereira, C. Autoetnografia, Filhos e Reflexividade Científica: Algumas Questões Metodológicas de Uma Investigadora Que Também é Mãe. Proc. CIAIQ 2019, 3, $18-27$.

18. Bernard, H.R. Research Methods in Anthropology-Qualitative and Quantitative Approaches, 4th ed.; Altamira Press: Lanham, MD, USA, 2006.

19. Lazard, L.; McAvoy, J. Doing reflexivity in psychological research: What's the point? What's the practice? Qual. Res. Psychol. 2020, 17, 159-177. [CrossRef]

20. Mason, J. Qualitative Researching, 2nd ed.; Sage: London, UK, 2002.

21. Au-Yong-Oliveira, M.; Silva, E. Observing from our own "cultural window"-Presenting autoethnographic narratives from tourism to music. In Proceedings of the 18th European Conference on Research Methodology for Business and Management Studies (ECRM) 2019, Wits Business School, Johannesburg, South Africa, 20-21 June 2019; Stacey, A., Ed.; ACPI: Reading, UK, 2019; pp. 51-60.

22. Lee, C.; Linkenauger, S.A.; Bakdash, J.Z.; Joy-Gaba, J.A.; Profitt, D.R. Putting like a pro: The role of positive contagion in golf performance and perception. PLoS ONE 2011, 6, 1-5. [CrossRef] [PubMed]

23. Cialdini, R.B. Harnessing the science of persuasion. Harv. Bus. Rev. 2001, 79, 72-81.

24. Abbas, A.; McLean, M. Becoming sociologists: Professional identity for part-time teachers of university sociology. Br. J. Sociol. Educ. 2001, 22, 339-352. [CrossRef]

25. Abdelbasset, E.y.; Malika, T.; Mohamed, R.; Said, B. Engineering of a training program for future teachers based on information and communication technologies. Int. J. Adv. Trends Comput. Sci. Eng. 2019, 8, 300-305. [CrossRef]

26. Saunders, M.; Lewis, P. Doing Research in Business and Management-An Essential Guide to Planning Your Project, 2nd ed.; Pearson Education: Harlow, UK, 2018. 
27. Saunders, M.; Lewis, P.; Thornhill, A. Research Methods for Business Students, 7th ed.; Pearson Education: Harlow, UK, 2016.

28. Ellis, C.; Adams, T.E.; Bochner, A.P. Autoethnography: An overview. Forum Qual. Soc. Res. 2011, 12, 1-18.

29. Ali-Khan, C.; Wesley White, J. Between hope and despair: Teacher education in the age of Trump. Educ. Philos. Theory 2020, 52, 738-746. [CrossRef]

30. Becker, K.L. Tell me your dreams and goals: Structuring communication exchanges to improve patient-centered care with chronic pain patients. Appl. Nurs. Res. 2020, 53, 151248. [CrossRef]

31. Mazur, E. Peer Instruction—A User's Manual; Prentice Hall: Upper Saddle River, NJ, USA, 1997.

32. Gardner, H. Five Minds for the Future; Harvard Business School Press: Boston, MA, USA, 2008.

(C) 2020 by the author. Licensee MDPI, Basel, Switzerland. This article is an open access article distributed under the terms and conditions of the Creative Commons Attribution (CC BY) license (http://creativecommons.org/licenses/by/4.0/). 